\section{Treatment of Tropical Sprue}

Unlike many diseases of the small intestine, tropical sprueas it affects Europeans and North Americans-responds to adequate treatment with a full remission. In the earlier stages the predominant deficiency is of folate, and the megaloblastic anaemia which develops after about four months responds fully to small doses of folic acid. ${ }^{12}$ Later a significant deficiency of vitamin $\mathrm{B}_{12}$ may occur, and if patients who have had tropical sprue for four years or longer are treated with folic acid alone subacute combined degeneration of the spinal cord may be precipitated. ${ }^{3}$ The haematological state may be further complicated in women by a severe iron deficiency.

There is less firm agreement about the treatment of the enteropathy of tropical sprue. When liver was introduced for the treatment of the megaloblastic anaemia it was found that not only was the anaemia relieved but the gastrointestinal symptoms also improved or cleared altogether. ${ }^{4}$ Moreover when T. D. Spies and his colleagues ${ }^{5}$ introduced treatment with folic acid they described a dramatic relief not only of the anaemia but also of the other symptoms of tropical sprue. Later workers, however, were less impressed with the curative effects of folic acid, for though there was symptomatic relief intestinal function tests showed continuing malabsorption, especially malabsorption of vitamin $B_{12}$. These adverse reports were mainly concerned with patients who had had tropical sprue of long duration; more recent work has again shown the therapeutic effect of folic acid on the intestinal lesion, ${ }^{67}$ and its efficacy seems to depend both on the duration of symptoms and the duration of treatment. ${ }^{8}$

Malabsorption of vitamin $B_{12}$ is rapidly corrected by treatment with oral broad-spectrum antibiotics, and this malabsorption precedes demonstrable morphological change in the ileal mucosa. ${ }^{9}$ In this sprue resembles the stagnant loop syndrome, and abnormal activity of the small intestinal bacterial flora may be of importance in its aetiology-as was suspected over fifty years ago by C. Begg, who used santonin in treatment ${ }^{10}$ not as an antihelminthic but for its action on small intestinal bacteria. In the second world war non-absorbable sulphonamides were found to be effective in controlling the diarrhoea of acute tropical sprue, and in 1954 the Birmingham group claimed ${ }^{11}$ an early and full remission in patients treated with a course of oral broad-spectrum antimicrobial drugs. The patients treated ${ }^{12}$ were seven soldiers with early sprue who had been flown to the United Kingdom from Hong Kong.

Sheehy, T. W., Rubini, M. E., Perez-Santiago, E., Santini, R., jun. and Haddock, J., Blood, 1961, 18, 623.

2 O'Brien, W., and England, N. W. J., British Medical fournal, 1964, 2, 1573.

3 Booth, C. C., and Mollin, D. L., American Fournal of Digestive Diseases, $1964, \mathbf{9}, 770$.

4 Rhoads, C. P., and Miller, D. K., Fournal of the American Medical Association, 1934, 103, 387

- Spies, T. D., Milanes, F., Menendez, A., and Minnach, V., fournal of Laboratory and Clinical Medicine, 1945, 30, 1056.

- Swanson, V. L., Wheby, M. S., and Bayless, T. M., American fournal of Pathology, 1966, 49, 167.

7 O'Brien, W., and England, N. W. J., British Medical fournal, 1966, 2, 1157.

${ }^{8}$ Klipstein, F. A., Gastroenterology, 1968, 54, 275.

9 O'Brien, W., American fournal of Clinical Nutrition, 1968, 21, 1007.

10 Begg, C., Sprue, its Diagnosis and Treatment. Bristol, Wright, 1912.

11 Anderson, C. M., Frazer, A. C., French, J. M., Hawkins, C. F., Ross, C. A. C., and Sammons, H. G., Gastroenterologia (Basel), 1954, 81, 98.

12 French, J. M., Gaddie, R., and Smith, N. M., Quarterly fournal of Medicine, 1956, 25, 333.

13 Sheehy, T. W., and Perez-Santiago, E., Gastroenterology, 1961, 41, 208.

14 Sheehy, T. W., Cohen, W. C., Wallace, D. K., and Legters, J., fournal of the American Medical Association, 1965, 194, 1069.
As with folic acid, subsequent reports have been less enthusiastic, ${ }^{13}$ but there seems little doubt that this regimen will produce a remission in many patients, including those with chronic tropical sprue. ${ }^{3}$

Except in early sprue the remission induced by folic acid or antimicrobial drugs alone may be slow or incomplete. If, however, folic acid (and in appropriate patients vitamin $\mathbf{B}_{12}$ ) and antimicrobial drugs are given together early and full remission occurs. ${ }^{914}$ Though the aetiology of tropical sprue is still obscure, it seems likely that the most promising lead lies in elucidating the reason for these responses.

\section{Fatal Puerperal Sepsis}

Over the past 30 years the chapters on puerperal sepsis in British obstetric textbooks have become thinner as the menace of childbed fever has receded. Nevertheless, the risk of death from infection after vaginal or abdominal delivery has not disappeared; indeed, if deaths from abortion are reclassified according to the cause of death then sepsis is the second commonest cause of maternal fatality.

The relevant figures from the latest report on maternal deaths in England and Wales are somewhat disconcerting. ${ }^{1}$ Deaths from puerperal sepsis declined sharply from 42 in 1952-4 to 18 in 1961-3, even though in the latter period there were almost half a million more births. But in 1964-6 the number rose to 28 , and there were 29 additional deaths from infection following obstetric operations. Of these, 25 followed Caesarean sections, most of which were performed after prolonged labour, and it is notable that a record $18 \%$ of these deaths were due to sepsis and paralytic ileus.

The continuing risk of maternal infection has also been noted in the U.S.A. In one hospital in Boston "childbed fever reached epidemic status" in early 1965, though fortunately there were no deaths. ${ }^{2}$ In Michigan in 1960-6 there was "a resurgence of infection as a primary cause of maternal death" with 55 fatalities, 31 of them following vaginal delivery. But, whatever the route of delivery, a long interval between rupture of the membranes and birth of the baby was an outstanding feature in all the fatal cases. ${ }^{3}$

Hence doctors must not be disarmed by past statistics. Trust in the potency of modern antibiotics must not lead them to relax the strict application of aseptic and antiseptic techniques, to allow labour to be unduly protracted, or to omit bacteriological investigations when infection may be foreseen as well as when it is clinically obvious. In the continuing fight against fatal puerperal sepsis the needs include a high standard of antenatal care, screening staff and patients for sources of infection, close day-to-day supervision of the labour suite by experienced obstetricians, giving antibiotics when infection is feared-and especially when rupture of the membranes, natural or artificial, is not quickly followed by progressive labour-the judicious use of oxytocin infusions to hasten delivery, and timely recourse to Caesarean section.

\footnotetext{
Arthure, H., et al., Report on Confidential Enquiries into Maternal Deaths in England and Wales 1964-1966. London, H.M.S.O. 1969.

2 Jewett, J. F., Reid, D. E., Safon, L. E., and Easterday, C. L., Fournal of the American Medical Association, 1968, 206, 344.

Stevenson, C. S., American Fournal of Obstetrics and Gynecology, 1969, 104, 699 .
} 